\title{
Response to: Letter to the Editor regarding: "Spontaneous regression of a clival chordoma. Case report"
}

\author{
Evan D. Bander ${ }^{1}$. Theodore H. Schwartz ${ }^{1}$ \\ Received: 17 December 2019 / Accepted: 19 December 2019 / Published online: 2 January 2020 \\ (C) Springer-Verlag GmbH Austria, part of Springer Nature 2020
}

\section{Dear Editor,}

We are grateful to Passeri et al. for their comments on our case report of a spontaneous regression of a clival chordoma. Their similar experience with a patient who had regression of a radiographically consistent clival chordoma after an episode of inflammatory bullous dermatosis, from an underlying Mycobacterium marinum infection, lends further support to the concept that chordomas can regress. The potential to uncover the underlying mechanisms of regression and tumor response in these reports can hopefully guide further drug discovery and screening in chordoma research.

However, despite the regression seen in these two reported cases, we would still recommend surgical resection over conservative follow-up imaging in a case such as the one they present. Maximal cytoreductive surgery and post-operative radiation are currently the most effective treatments for chordoma [1,3]. While the patient in their case is currently asymptomatic, the size of the tumor and extent of brainstem compression present a significant risk for future deterioration. If this tumor were to grow, it could cause permanent irreversible deficits and the surgery would be more challenging and riskier at that point. The fact that the tumor has now partially decreased in size also makes it more amenable to surgical resection. Confirmatory pathology and histologic assessment could also lend support to an underlying mechanism of regression in their case. Resection through an endoscopic endonasal approach could be considered [2, 4].

\section{References}

1. Di Maio S, Temkin N, Ramanathan D, Sekhar LN (2011) Current comprehensive management of cranial base chordomas: 10-year meta-analysis of observational studies. J Neurosurg 115(6):1094-1105

2. Fraser JF, Nyquist GG, Moore N, Anand VK, Schwartz TH (2010) Endoscopic endonasal transclival resection of chordomas: operative technique, clinical outcome, and review of the literature. J Neurosurg 112(5):1061-1069

3. Walcott BP, Nahed BV, Mohyeldin A, Coumans J-V, Kahle KT, Ferreira MJ (2012) Chordoma: current concepts, management, and future directions. Lancet Oncol 13(2):e69-e76

4. Zoli M, Milanese L, Bonfatti R et al (2017) Clival chordomas: considerations after 16 years of endoscopic endonasal surgery. J Neurosurg 128(2):329-338

Publisher's note Springer Nature remains neutral with regard to jurisdictional claims in published maps and institutional affiliations.
This article is part of the Topical Collection on Brain Tumors

Theodore H. Schwartz

schwarh@med.cornell.edu

1 Department of Neurosurgery, Weill Cornell Medicine, New York Presbyterian Hospital, 525 East 68th St., Box \#99, New York, NY 10065, USA 